\title{
Evaluation and remediation of post-wildfire slope stability
}

\author{
Mahta Movasat $^{1}$ and Ingrid Tomac ${ }^{1}$ \\ ${ }^{1}$ Structural Engineering Department, University of California San Diego, 9500 Gilman Drive, La Jolla, CA 92093-0085, USA
}

\begin{abstract}
Catastrophic mudflows and landslides triggered by rainfall can occur suddenly and move with high speed, damaging electrical and civil infrastructure and threatening human and wildlife. Due to the climate change and extreme weather increase, it is likely that wildfires and consequently mudflows will increase in frequency in the future. The risk of mudflows and landslides increases in post-wildfire areas mainly because of water repellent soil which forms on slopes. Water repellency, or hydrophobicity, can occur due to the burning of the accumulated organic matter in soil. Hydrophobicity repels water and prevents infiltration of water into the soil, which results in soil erosion, mudflows and landslides. In this study, a series of experimental laboratory tests are conducted on regular, hydrophobic and Xanthan gum-treated hydrophobic sand. Xanthan gum, which is an environmentally friendly biopolymer, can be substituted for chemical material used for soil improvement and decrease the $\mathrm{CO}_{2}$ emissions and enhance environmental slope protection. Xanthan gum can enhance the inter-particle cohesion and can hold a large amount of water and consequently help the recovery of the vegetation. Contact angle, direct shear and rain simulation tests are conducted on samples. Results show that in Xanthan gum treated slope the rate of erosion and the risk of mudflow decreases. It is also observed that the Xanthan gum treated sample can retain more water and consequently decreases the rate of wind erosion and helps the dust-control in burned areas.
\end{abstract}

\section{Introduction}

Water repellency or hydrophobicity is a chemical modification of soil grain surface property which affects the wetting process, hydrological process of water flow, drainage and infiltration in soil. It is believed that repellency is caused by volatilization of (hydrophobic) waxes originated from incomplete combustion of organic matter subsequently condensing and coating soil particles [1-2]. Water-repellent soil is aroused by dry periods. Wildfires or intense heating of soil are known to be a primary reason of water repellency of soil. Other reasons are plant roots exudates, certain fungal species and surface wax from plant leaves and oil spills. In California, [3] reported wildfires on chaparral watersheds produced water repellent soil.

Wildfires can cause different levels of hydrophobicity based on fire severity, vegetation and chemical structure of the soil [3]. Change in hydrological process, loss of vegetation, increase in the erosion rate, flooding and recently seen catastrophic mudslides are consequences of post-fire water repellency in soils. Besides, hydrophobicity can cause preferential flow in soil which can affect plant growth and can lead to rapid contamination of ground water by faster transport of water and solute [4]. Furthermore, soil hydrophobicity is responsible for the increase of soil erosion. The rate of soil erosion can increase more than one order of magnitude in forests which have experienced wildfires [5]. Numerous debris flow and erosion events following the fire in western United States have been reported as well. A torrential rainfall at hillslopes of Storm King Mountain in Colorado caused debris-flow in this region, which was burned earlier by a wildfire [6]. Debris flows in Southern British Columbia is another example of postfire debris flow and floods [7].

Prevalence of water repellent soils indicates the importance of the development of the methods to characterize the degree of repellency. Water drop penetration time and contact angle measurements between the solid and liquid phases are two methods of characterizing the magnitude of water repellency [8]. If a drop of water is placed on a hydrophobic surface it will not spread as it would happen in hydrophilic soil. In hydrophobic soils under natural conditions, the surface energy is low due to the presence of the organic particles on the surface. This low surface energy results in low attraction between solid and liquid and consequently water beads on the surface and a larger contact angle can be observed. Sessile drop method is a way to measure the water contact angle [9]. Generally, if the water contact angle is smaller than $90^{\circ}$, the solid surface is considered hydrophilic and if the water contact angle is larger than $90^{\circ}$, the solid surface is considered hydrophobic [10]. Some materials with highly rough surfaces may have a water contact angle even greater than $150^{\circ}$, due to the

\footnotetext{
*Corresponding author: mmovasat@eng.ucsd.edu
} 
presence of air pockets under the liquid drop. These are called super hydrophobic surfaces.

Numerous soil treatment techniques can be used for enhancing the soil properties such as aggregate stability, strength, and erosion resistance. Among these techniques, cement is one of the most commonly used soil treatment methods. However, cement is responsible for a massive amount of $\mathrm{CO}_{2}$ emission, which consequently leads to a lot of environmental issues. Nowadays, environmentally friendly biopolymers can be suitable replacement for conventional materials. Xanthan gum which is an environmentally friendly biopolymer can be substituted for chemical material used for soil improvement and decrease the $\mathrm{CO}_{2}$ emissions and enhance environmental slope protection. Xanthan gum is a polysaccharide commonly used as a food additive and rheology modifier; it is produced by fermentation of glucose or sucrose by the Xanthomonas campestris bacterium. Xanthan gum has a hydrophilic surface, shows high stability under a wide range of temperatures and $\mathrm{pH}$ and increases the viscosity [10-11]. It is also shown that Xanthan gum as an effect of strengthening on different types of soil [13].

This study uses experimental laboratory approaches to better understand the triggering process of a splasherosion which leads to a mudflow in water repellent slopes during rainfall and to investigate the potential of using Xanthan gum biopolymer as a treatment to remediate soil erosion. Two water repellent slope and Xanthan gum treated slopes are compared during the rainfall experiment. Water contact angle tests are also conducted to observe the difference between the hydrophilic and hydrophobic soil samples.

\section{Methodology}

\subsection{Hydrophobic soil preparation}

Ottawa F-65 sand, which is a round grain, silica sand is used in this research. Ottawa F-65 sand is also used to make artificial hydrophobic soil in laboratory. The artificial hydrophobic soil is prepared in three steps. The first step is to oven dry the sand for 48 hours. The second step is to submerge the oven-dried sand in a $10 \% \mathrm{n}$ octyltriethoxysilane and $90 \%$ isopropyl-alcohol solution by volume for 48 hours and finally, the sand is washed to remove any reactive compound and oven-dried for 24 hours [14], [15].

\subsection{Water Contact Angle Measurement by Sessile Drop Method}

A firm rough surface should be provided in order to have a precise measurement. To achieve this purpose, a double-sided adhesive tape is fixed on a microscopic glass and oven-dried soil is sprinkled on the $2 \times 2 \mathrm{~cm}$ tape from a $10 \mathrm{~cm}$ height. After sprinkling the soil on the tape, a $100 \mathrm{gr}$ weight is used to press the soil particles to the tape and the glass is tapped carefully to remove the excess soil. This procedure is repeated two times for all the samples. Five drops of deionized water are placed on the soil layer by a pipet (each drop's volume is $1.7 \mathrm{~mm}^{3}$ ). Images of the droplet on the surface are taken immediately and ten minutes after placing the water drops on the surface. High speed Phantom camera is used to take images and videos of the experiment with a resolution of $640 \times 480$ pixels. Each test is repeated 3 times to ensure the accuracy of the measured angles.

\subsection{Rainfall Simulation Test}

A laboratory-scale rain simulator is designed and built to study the soil erosion and mudflow in hydrophobic slopes. The experimental setup is built in the Geomechanics laboratory of the University of California San Diego. The rain simulator setup is built an acrylic sand box, pumping system and a nozzle, and a supporting PVC frame, as shown in Fig. 1.a. Rain intensity, flow rate, and spatial uniformity are considered as the most important factors for controlling rain simulations and investigating surface erosion mechanisms. The acrylic box has the dimensions of $30 \times 120 \mathrm{~cm}$ and a depth of 20 $\mathrm{cm} .15 \mathrm{~cm}$ out of this $20 \mathrm{~cm}$ from the bottom is used to prepare the sand layer and $5 \mathrm{~cm}$ remaining part is allocated for runoff observation. The acrylic sand box is divided into two flumes.

An acrylic runoff funnel is attached to collect the water and sand particles at the end of each flume. The angle of the box is fixed at $20^{\circ}$ from horizontal surface. The rain intensity is selected based on the $13 \mathrm{~mm}$ in five minutes rain intensity reported for the recent rain in Santa Barbara County which caused a mudflow in this area. [16]. The nozzle used for this experiment is BETE$W L 1$ full cone nozzle with a $90^{\circ}$ spraying angle. The single nozzle is attached to the center of the PVC support frame, above the center of the acrylic box at a height of $1.5 \mathrm{~m}$, such that the radius of raining can cover the whole box for a homogenous precipitation (Fig. 1.a). The target rain intensity is $16 \mathrm{~cm} /$ hour and the flow rate needed for this intensity is $0.1 \mathrm{~m}^{3} /$ hour with a pressure of $68.9 \mathrm{kPa}$.

Four volumetric water content sensors are installed along the central line of each flume as shown in Fig. 1.b. Two sensors are embedded in a depth of $3 \mathrm{~cm}$ from the sand surface in each flume. Ports 1 and 3 are located at $25 \mathrm{~cm}$ distance from the top of the box and ports 2 and 4 are in $75 \mathrm{~cm}$ distance from the top of the box. The soil layout in both flumes is described as following: an $8 \mathrm{~cm}$ thick bottom layer with coarser sand, $5 \mathrm{~cm}$ thick hydrophilic sand and a $2 \mathrm{~cm}$ thick hydrophobic layer at the top with a relative density of $40 \%$ for the two top layers. Sand was not compacted after placing into the container in the experiment, since surface processes were of interest. The first flume is treated with Xanthan gum

\footnotetext{
Corresponding author: mmovasat@eng.ucsd.edu
} 
and it represents the treated slope (see Fig 2). Xanthan gum is mixed by hand in a dry condition with dry hydrophobic sand at a $4 \%$ weight ratio of Xanthan gum $\left(\mathrm{w}_{\mathrm{xanthan}} / \mathrm{w}_{\text {sand }}\right)$ and then the mix is poured as a $2 \mathrm{~cm}$ thick layer on the surface.

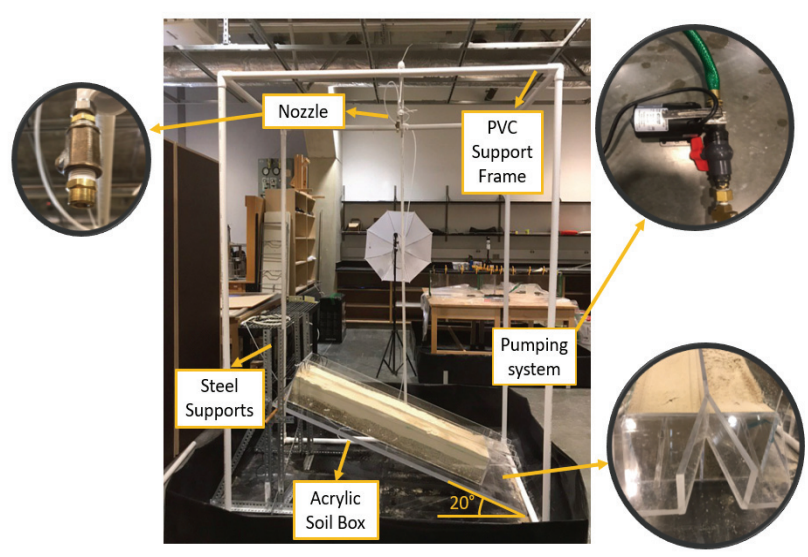

a

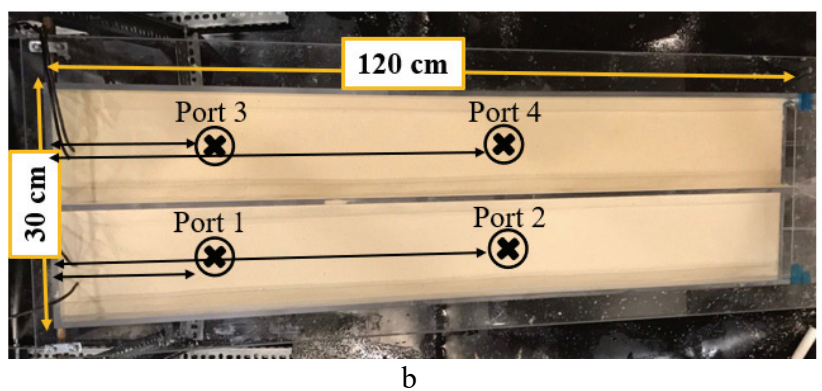

Fig. 1. a) Rainfall experiment setup b) Layout of Volumetric water content sensors

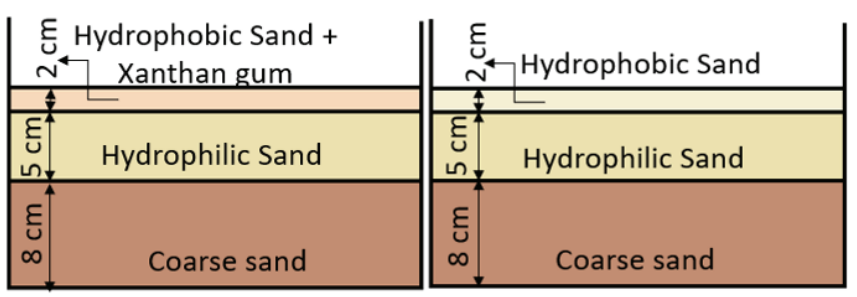

Fig 2. Soil layers cross section

\section{Experimental results}

High speed Phantom camera is used to take images and videos of the experiment with a resolution of $640 \times 480$ pixels. Water contact angle measurement results show that the artificial hydrophobic soil has a larger contact angle. The water contact angle right after placing the water drop is $115^{\circ}$ in hydrophobic sand, while it is $61^{\circ}$ in hydrophilic sand. After ten minutes the water contact angle decreases to $100^{\circ}$ in hydrophobic soil and it drops almost $40 \%$ from its initial value to $37^{\circ}$ in hydrophilic case. This shows a higher rate of drop in hydrophilic sands, while the change in hydrophobic sand is low. The higher contact angle in hydrophobic soil indicates the low surface energy on the hydrophobic surface.
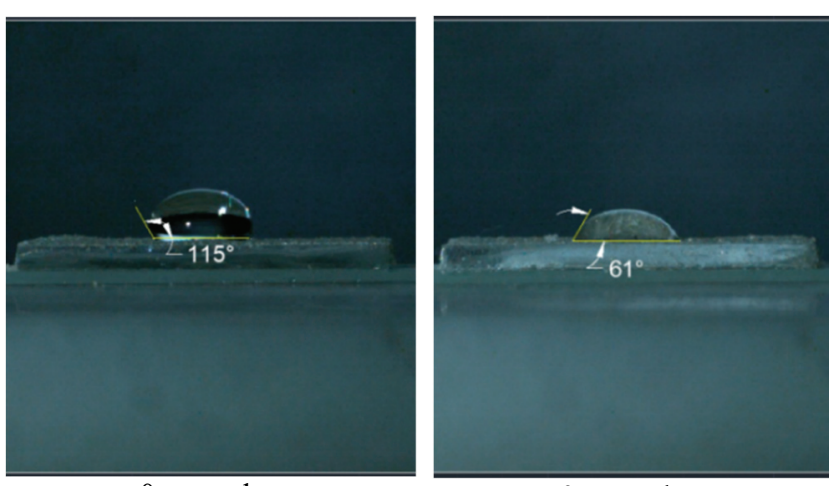

0 seconds
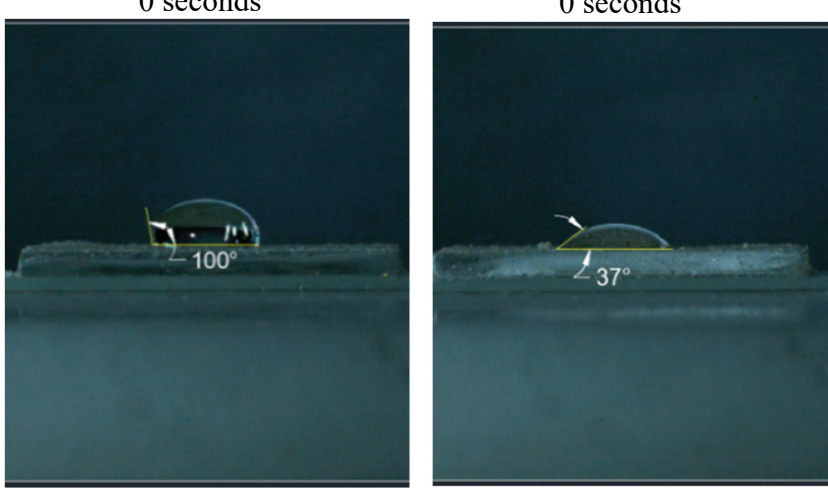

10 minutes

10 minutes

Fig. 3. Contact angle measurements in hydrophobic (Left column) and hydrophilic (Right column) soils

In the rainfall experiment, as it is shown in Fig 2 the left flume's top sand layer is treated with Xanthan gum biopolymer. During the experiment the overflow water and soil was collected continuously in 10-minute intervals and after measuring the total volume, the remaining soil was oven-dried and then weighted. The amount of water overflow and eroded sand content for hydrophobic and treated hydrophobic flumes are shown in Fig. 4. As shown in Fig. 4.a, the amount of overflow water changes between $1300 \mathrm{ml}$ and $1800 \mathrm{ml}$ in tenminute intervals for treated hydrophobic flume while it decreases from $1300 \mathrm{ml}$ to approximately $400 \mathrm{ml}$ in the hydrophobic flume. This indicates that after the hydrophobic layer starts eroding at the toe, the water starts to infiltrate into the underlying regular sand layer. However, on the other slope, which is treated by Xanthan gum, the water cannot infiltrate due to the formation of a protective layer. Fig. 4b shows that the amount of collected sand from the treated hydrophobic slope is truly negligible compared to the amount collected from the hydrophobic slope. 


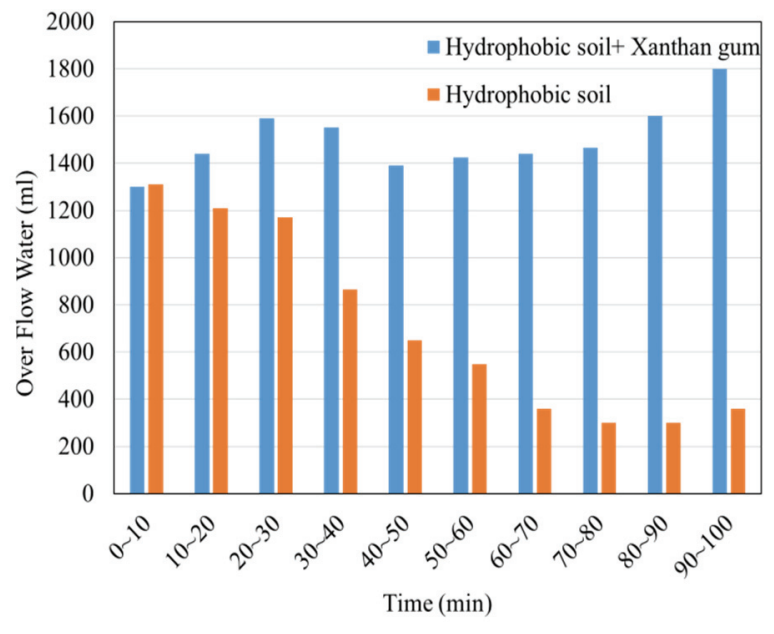

a

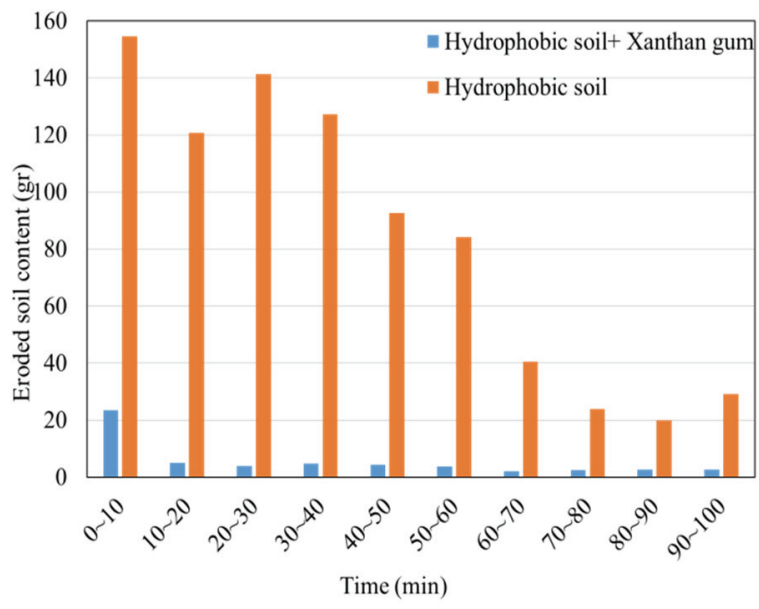

$\mathrm{b}$

Fig. 4. a) Overflow water collected from each flume in 10 minutes intervals. b) Eroded sand content collected from each flume

Fig. 5.a illustrates the condition of the sand surface in both flumes at the end of the second test. In the right side flume, the erosion starts from the toe immediately after the rain starts and the hydrophobic layer in this part is removed by water drops and surface water flow (see Fig. 5.b). The flume in the left, which is treated with Xanthan gum shows no significant change in surface and it is observed that Xanthan gum creates a protective jelly layer over the sand surface after a few minutes of raining and protects the sand from being moved by water. However, in hydrophobic slope after the rain begins, sand particles are displaced and moved easily by water. Volumetric water content remains constant during the test in both flumes since there is no significant infiltration of water near the sensor location in any of the flumes. Most of the water infiltration is observed at the toe part of the hydrophobic slope in which the hydrophobic layer is completely removed by erosion.
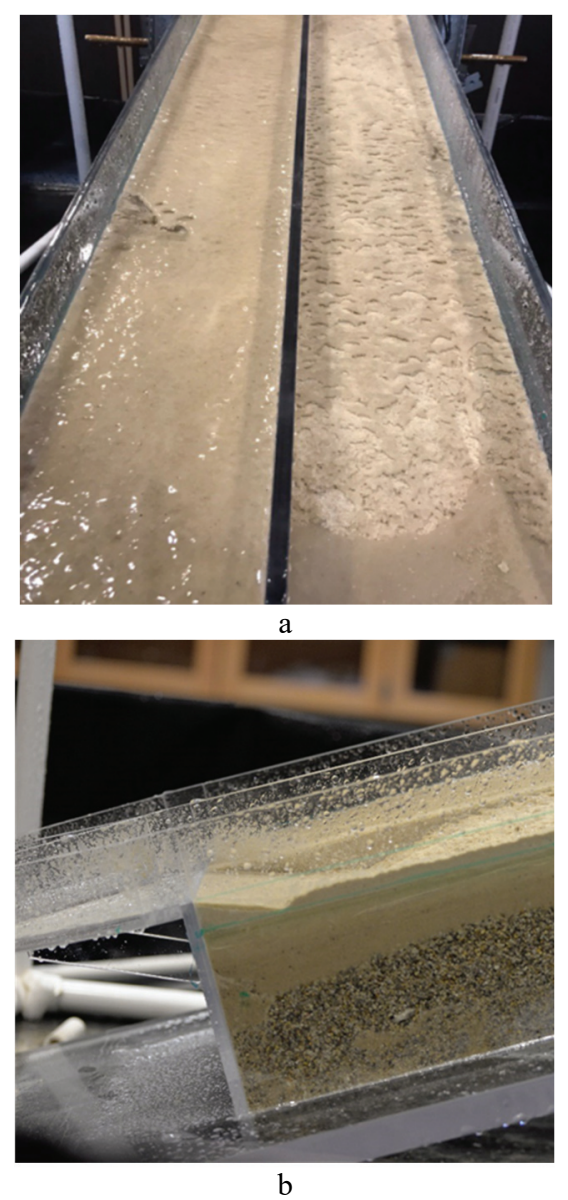

Fig. 5. a) The final condition of the two flumes after rain. The left flume represents the treated hydrophobic sand with $4 \%$ Xanthan gum and the right flume represents the hydrophobic slope. b) The final condition of the hydrophobic slope toe.

\section{Conclusions}

Fire induced hydrophobicity has a significant effect on granular soil erosion on slopes, loss of vegetation, flooding and catastrophic mudslides. This paper investigates and compares soil water contact angle and time-dependent change of the angle in hydrophobic and hydrophilic soil. Besides, soil erosion and run-off amount in Xanthan gum-treated and untreated hydrophobic soil is compared. Water contact angle measurements by using sessile drop method and rainfall experiments under the rain intensity of $17 \mathrm{~cm} /$ hour for 100 minutes were conducted for two specimens. Water contact measurements indicate an initial angle of $115^{\circ}$ for hydrophobic sand and $61^{\circ}$ angle for hydrophilic sand. The larger contact angle in hydrophobic sand indicates a lower surface energy in hydrophobic surface. It is observed that, after ten minutes the water contact angle drops $13 \%$ from its initial value in hydrophobic soil and it drops almost $40 \%$ from its initial value in hydrophilic case.

\footnotetext{
* Corresponding author: mmovasat@eng.ucsd.edu
} 
For the rainfall experiment, hydrophobic and Xanthan gum-treated hydrophobic slopes were tested under identical rainfall conditions. The hydrophobic sand was mixed with $4 \%$ Xanthan gum in the top $2 \mathrm{~cm}$ from the surface and the raining experiment was conducted. After the rain started, in Xanthan-gum treated slope, a jelly layer developed and protected the sand from being eroded and the treated sand surface remained almost undamaged. The amount of overflow water in Xanthan gum-treated slope changes between $1300 \mathrm{ml}$ and $1800 \mathrm{ml}$ in ten-minute intervals, while it decreases from $1300 \mathrm{ml}$ to approximately $400 \mathrm{ml}$ in the hydrophobic flume. Almost all the rain flowed over the treated sand without significant erosion, damage and soil removal. However, the volumetric water content sensor measurements revealed decreased the ability of sand to absorb water during the test, and it didn't decrease the water overflow.

\section{References}

1. L. F. DeBano, "Water repellent soils: a state-ofthe-art," United States Dep. Agric. Gen. Tech. Rep. PSW-GTR-46, pp. 1-21, 1981.

2. S. H. Doerr, R. A. Shakesby, and R. P. D. Walsh, "Soil water repellency: Its causes, characteristics and hydro-geomorphological significance," Earth Sci. Rev., vol. 51, no. 1-4, pp. 33-65, 2000.

3. L. F. Debano and J. S. Krammes, "Water repellent soils and their relation to wildfire temperatures," Int. Assoc. Sci. Hydrol. Bull., vol. 11, no. 2, pp. 14-19, 1966.

4. Z. Wang, Q. J. Wu, L. Wu, C. J. Ritsema, L. W. Dekker, and J. Feyen, "Effects of soil water repellency on infiltration rate and flow instability.pdf," vol. 232, pp. 265-276, 2000.

5. D. F. Scott and D. B. Van Wyk, "The effects of wildfire on soil wettability and hydrological behavior of afforested chatchement," vol. 118, pp. 239-256, 1990.

6. S. H. Cannon, R. M. Kirkham, and M. Parise, "Wildfire-related debris-flow initiation processes," Geomorphology, vol. 39, pp. 171$188,2001$.

7. P. Jordan and S. A. Covert, "Debris flows and floods following the 2003 wildfires in Southern British Columbia," Environ. Eng. Geosci., vol. 15, no. 4, pp. 217-234, 2009.

8. J. Letey, J. Osborn, and R. Pelishek, "Measurement of liquid-solid contact angles in soil and sand," Soil Sci., vol. 93, no. 3, pp. 149-
153,1962

9. J. Bachmann, R. Horton, R. Van Der Ploeg, and S. Woche, "Modified sessile drop method for assessing initial soil--water contact angle of sandy soil," Soil Sci. Soc. Am. J., vol. 64, no. 2, pp. 564-567, 2000.

10. W. A. Zisman, "Contact angle, wettability, and adhesion,” Adv. Chem. Ser., vol. 43, p. 1, 1964.

11. M. Zohuriaan and F. Shokrolahi, "Thermal studies on natural and modified gums," Polym. Test., vol. 23, no. 5, pp. 575-579, 2004.

12. S. Rosalam and R. England, "Review of xanthan gum production from unmodified starches by Xanthomonas comprestris sp.," Enzyme Microb. Technol., vol. 39, no. 2, pp. 197-207, 2006.

13. I. Chang, J. Im, A. K. Prasidhi, and G. C. Cho, "Effects of xanthan gum biopolymer on soil strengthening," Constr. Build. Mater., vol. 74, no. $x$, pp. 65-72, 2015.

14. M. Z. Karim, S. E. Tucker-Kulesza, and M. M. Derby, "Synthesizing hydrophobic sand and comparison of shear strength properties with hydrophilic sand," pp. 75-83, 2018.

15. C. Lee, H.-J. Yang, T. S. Yun, Y. Choi, and S. Yang, "Water-entry pressure and friction angle in an artificially synthesized water-repellent silty soil," Vadose Zo. J., vol. 14, no. 4, p. 0, 2015.

16. J. Schleuss, D. Smith, and B. Boxall, "Tracking a path of destruction from Montecito's mountains to the ocean.," Los Angeles Times, 2018.

*Corresponding author: mmovasat@eng.ucsd.edu 